\title{
Anchoring and relational judgments by young children and retardates*
}

\author{
TED L. ROSENTHAL $\dagger$, JOHN E. KELLEY, and GLENN M. WHITE \\ University of Arizona, Tucson, Arizona 85721
}

\begin{abstract}
In five experiments using as dimensions brightness, texture, facial happiness, height, and weight, young children (ages 3.4 to 5.3 years) rendered bipolar judgments of stimuli intermediate in value between alternately given extreme anchors. Consistent relational shifts away from the anchors were found for all dimensions judged, and these effects proved virtually independent of children's ages, the sequential orders of stimulus and anchor presentation, or the provision of overt visual memory props. Evidence of relational judgment within the narrower range of the test stimuli alone was also found. Essentially similar relational judgments were replicated with a sample of severe adult mental retardates.
\end{abstract}

In previous research, O'Reilly and Steger (1970) found that children 6 years and older were able to make relative judgments of a series of weights, and then shifted their judgments when a light anchor stimulus was introduced. However, 5-year-olds were unable either to order the weight series correctly or to "reflect any awareness of the anchor [O'Reilly \& Steger, 1970, p. 1097]." With their procedures, one must note that children never actually hefted weights but instead pulled levers that were attached to invisible weights. Also, judgment responses were measured indirectly by having the child point at pictures of bell-shaped weights that formed an increasing size series to represent relative heaviness. It, thus, seemed possible that such complex and indirect methods (lever $=$ weight, size of picture $=$ heaviness) may have acted to the detriment of the younger Ss. Perhaps young children could cognize relational stimulus differences if given the opportunity to respond in a simpler, more direct fashion. By using simple response formats, one may demonstrate better comprehension by young children than if response is indexed by more subtle procedures, a point elsewhere discussed (Rosenthal \& White, 1972).

Social judgment theory (e.g., Helson, 1964; Sherif \& Hovland, 1961) and social learning theory (e.g., Bandura, 1969, 1971; Rosenthal \& Zimmerman, 1972) hold that abstract judgments depend on the immediate and prior dimensional contexts against which the relevant stimuli are judged. In this view even very young children should respond in relation to altered frames of reference. A substantial change in prior experience or a strong shift in immediate contextual features, should

*This paper is based on an MA thesis submitted to the Department of Psychology, University of Arizona, in partial fulfillment of degree requirements. We are deeply grateful for the generous cooperation of Jean $R$. Dees and her staff at the University of Arizona Laboratory Preschool and of Paul D. Wulkan and Ridgely W. Chambers and their staff at the Arizona Training Programs at Tucson.

$\dagger$ Request for reprints should be sent to Ted L. Rosenthal, Department of Psychology, University of Arizona, Tucson, Arizona 85721. produce displacement of judgments for any discriminable stimulus dimension, whether physical or social.

The present experiments with very young children explored anchoring effects of extreme values given for both poles of the dimensions of brightness, texture, facial happiness, height, and weight. Also studied were children's discrimination of the slight quantitative differences among each triad of test stimuli when no extreme anchors were provided. To determine if judgments were based on relational cognitions mediated by memory, for the visual dimension half of the Ss did or did not have visual access to the last anchor stimulus given when making their judgments. To assess the generality of the judgmental results, the same essential experiments were replicated with a sample of institutionalized, severely retarded young adults.

\section{METHOD}

Experiments 1-5

\section{Subjects}

From children enrolled in a nursery school, eight boys and eight girls were randomly drawn from each of two age groups. The younger children ranged from 3.4 to 4.2 years $(\bar{X}=3.8$ years) and the older group ranged from 4.3 to 5.3 years $(\bar{X}=4.6$ years).

\section{Stimulus Materials}

Each judgmental dimension involved three somewhat different test stimuli and, at each extreme of the dimension, three identical end-anchors. For brightness, all stimuli were circles of $5.1-\mathrm{cm}$ radius painted on $17.8 \times 17.8 \mathrm{~cm}$ white posterboard squares. The bright end-anchors reflected $88.5 \%$ of natural sunlight striking them; the reflectance of the dark end-anchors was $3.8 \%$; and the intermediate triad of test stimuli had reflectances of $16.0 \%, 24.8 \%$, and $36.9 \%$. Judgments of light intensity were elicited in terms of "bright" vs "dark" labels. For texture, all stimuli were $10.2 \times 10.2 \mathrm{~cm}$ abrasive paper squares centered on $17.8 \times 17.8 \mathrm{~cm}$ posterboards. The rough end-anchors were 36 grit; the smooth end-anchors were 600 grit; and the three test stimuli were 80,150 , and 240 grits. The judgment poles were labeled "rough" and "smooth." For the 
social dimension of facial happiness, all stimuli were circles of $5.1-\mathrm{cm}$ radius drawn on $17.8 \times 17.8 \mathrm{~cm}$ posterboards. Two black dots were placed symmetrically $1.9 \mathrm{~cm}$ to the left and to the right of the vertical bisector and $2.6 \mathrm{~cm}$ above the horizontal bisector of each circle. The happy end-anchors had upward arcs of $3.2-\mathrm{cm}$ radius for mouths; the sad anchors had identical arcs but inverted; the intermediate test stimuli were a straight line and upward (slightly happy) and downward (slightly sad) shallower arcs for mouths. The judgment poles were labeled "happy" and "sad." For height, all stimuli used strips of black tape $7 \mathrm{~mm}$ wide, each placed on a $17.9 \times 35.6 \mathrm{~cm}$ white posterboard rectangle. The tall end-anchors were strips $30.5 \mathrm{~cm}$ high; the short end-anchors were $5.1 \mathrm{~cm}$ high; and the heights of the test stimuli were $15.2,17.8$, and $20.3 \mathrm{~cm}$. The judgment poles were labeled "tall" and "short." For weight, all stimuli were constructed from like-sized frozen orange juice cans, painted flat black, and with taut black cloth taped to their tops. All cans were, thus, visually homogeneous but contained varying amounts of lead. The heavy end-anchors weighed $1135 \mathrm{~g}$, the light end-anchors $27 \mathrm{~g}$, and the test stimuli weighed 481,567, and $767 \mathrm{~g}$. The judgment poles were labeled "heavy" and "light." A more extensive description of the stimulus materials, and of all the procedural details, was elsewhere provided (Kelley, 1973).

\section{Overview and Experimental Variations}

The research consisted of three phases, each conducted an average of 14 days apart. In all sessions the child was tested on the five dimensions in the randomly predetermined order of brightness, texture, facial happiness, height, and weight. For each dimension the three test stimuli were exposed in one of two formats that remained constant once the child had been assigned to a test order condition. The first order presented the test stimuli by dimension as follows: median value, brighter stimulus, darker stimulus; median, rougher, smoother; median, happier, sadder; median, taller, shorter; and median, heavier, lighter. The alternative order reversed the nonmedial test stimuli, e.g., median, darker, lighter; median, smoother, rougher, etc.

$A$ random procedure was used to determine which anchor stimuli would covary with each other across experiments (dimensions) during Phases I and II. The first anchor sequence gave bright, smooth, happy, short, and heavy anchors. The second sequence gave dark, rough, sad, tall, and light anchors. Equal numbers of children by sex and age level were randomly assigned to an anchor sequence for Phase I and then got the opposite anchor sequence during Phase II. Thus, if a child received dark and rough anchors in Phase $I$, he subsequently received bright and smooth anchors in Phase II, etc.

The visual dimensions permitted the provision or omission of a memory prop, simply by allowing or preventing the final anchor to remain visible while the child made his judgments. Thus, half of the children in each age and sex group gave all their visual judgments with an anchor showing, and no anchor prop was available to the remaining Ss. Judgments of the texture dimension were made with the child's eyes shut. During Phase III, anchors were never presented, and the children's judgments were only based on the differences among the three test stimuli for each dimension.

\section{Procedure}

The child was seated at a low table across from the male adult $E$ in a small office. All anchor and test stimuli were presented individually. In Phases $I$ and $I I$, the $E$ first introduced the anchors by holding them aloft (if visual) or by placing them in contact with the child's hand (for texture and weight). Stimuli were exposed for $5 \mathrm{sec}$, with some $5-8 \mathrm{sec}$ between presentations. Other than the weights, all anchor stimuli were discarded face down, except for the final visual item in the anchor-present condition. Test stimuli were judged while still held aloft by the $\mathrm{E}$ or while in the child's hand (if nonvisual). Upon completing a test dimension, its stimuli were concealed in a discard pile before introducing the next dimension. A bipolar verbal judgment was elicited for each test stimulus.

Instructions were essentially identical across phases, except for opening and closing remarks and the elimination of anchor-relevant directions during Phase III. No reinforcement, praise, or other verbal guidance was ever administered to the children's ongoing judgments. The basic instructions for Phases I and II were as follows:

"Okay (child's name), we're going to play some games and do some things. Look at this circle (anchor). Look at this circle (anchor). Look at this circle (anchor). Now look at this circle. Is it bright or dark? Now look at this circle. Is it bright or dark? Now look at this circle. Is it bright or dark? Now we'll do something different. Close your eyes. Touch this (anchor). Touch this (anchor). Touch this (anchor). Keep your eyes closed and now touch this. Is it rough or smooth? Now touch this. Is it rough or smooth? Now touch this, Is it rough or smooth? Now we'll do a new thing. Look at this face (anchor). Look at this face (anchor). Look at this face (anchor). Now look at this face. Is it happy or sad? Now look at this face. Is it happy or sad? Now look at this face. Is it happy or sad? Let's try something else. Look at this line (anchor). Look at this line (anchor). Look at this line (anchor). Now look at this line. Is it tall or short? Now look at this line. Is it tall or short? Now look at this line (anchor). Is it tall or short? Okay. Now we'll play a very different game. Lift up this can (anchor). Lift up this can (anchor). Lift up this can (anchor). Now lift up this can. Is it heavy or light? Now lift up this can. Is it heavy or light? Now lift up this can. Is it heavy or light? Wonderful (child's name), we're all done, etc."

After completing his judgments, the E thanked the child and allowed him to stick three colored stars at the corner of a dittoed triangle to keep as a souvenir and to serve as a distraction from the judgment task before the child rejoined his group's ongoing activities.

\section{Scoring}

Since no absolute scoring criteria were possible, one endpoint of each dimension (e.g., dark, rough, etc.) was arbitrarily selected as a scoring standard. If a response was the same as that endpoint, it received a score of 1 , with a possible score range from 0 to 3 per phase, and the set of these summed scores per phase constituted the raw data for the main analysis of variance of that experiment. Statistically, relational judgment effects would emerge as an interaction between anchor sequence and phases. The main predictions showing relational judgments would be best supported by a pattern of "crossovers" between the anchor sequence groups and the means of Phases I and II.

Within each phase and dimension, the three test stimuli differed in value. It was, thus, possible to examine if the children (independent of any prior anchors) judged the test stimuli relationally. For example, if the first test stimulus was judged as bright and the second test stimulus was darker, only a judgment of "dark" would be relational. Or, if the second test stimulus was judged as smooth and the third stimulus was of finer grit, only a judgment of "smooth" was scored as relational for the third stimulus. Two such comparisons were possible for each set of test stimuli, and by these criteria a child could give zero, one, or two relational judgments among test stimuli per dimension per phase. Each relational judgment was arbitrarily scored as +1 and each nonrelational judgment as -1 . For each phase of each experiment, the departure of the mean so computed from the null hypotheses of no population difference (i.e., $\mu=0$ ) was evaluated by a $t$ test for a single mean (McNemar, 1962, p. 101). One can see that these (two-tailed) $t$ results would be of special interest for Phase III when no end-anchors, only the test stimuli, were presented. These $t$ comparisons were conservative both because they ignored the effects of the prior, extreme anchors 
given in Phases I and II and because theory does not require that a relational change be judged for each such possibility permitted by the stimulus values.

\section{Design}

For the visual dimensions, the major statistical analyses involved a 2 (age) by 2 (test-stimulus order) by 2 (anchor sequence) by 2 (presence or absence of a visual anchor while judging) by 2 (phases) factorial design. Providing or omitting the visual anchor prop was not a variable in analyzing the texture and weight experiments. Scheffé tests were used for specific comparisons, and all significance levels reported were based on two-tailed probability estimates. The present paper summarizes the main findings, which are more extensively presented elsewhere (Kelley, 1973). Although sex of child was equated across conditions, this was a control procedure and sex is not further discussed in the results. However, subsidiary analyses revealed no significant main effects for sex in any experiment and, generally, sex of $S$ played a negligible role in all result (Kelley, 1973).

\section{Experiments 6-10}

\section{Subjects}

From a training school for severe mental retardates, 16 adults were randomly drawn from a very dull (work skills) group; they ranged in age from 16 to 30 years $(\overline{\mathrm{X}}=21.8$ years). From a less extremely retarded (prevocational) group, 16 adults were also drawn; they ranged in age from 19 to 36 years $(\bar{X}=25.2$ years). Previous research has confirmed the differential learning ability of these retardate groups (Rosenthal \& Kellogg, in press) Although equal numbers of men and women were included, it was not possible to entirely balance the sexes in the ability groups across the experimental conditions.

\section{Procedures, Scoring, and Design}

All scoring and experimental procedures were the same as described for the children, except that the postjudgments distraction of pasting stars on a triangle was omitted. In the statistical analyses, ability level (higher or lower) replaced the age variable studied with the children. Otherwise, the methodology was identical for the children and the adult retardates.

\section{RESULTS}

Table 1 presents the mean number of polar judgments

Table 1

Mean Number of Polar Judgments by Phase and Anchor Sequence Group for Children and Retardates

\begin{tabular}{|c|c|c|c|c|c|}
\hline \multirow{2}{*}{$\begin{array}{c}\text { Judgment } \\
\text { (by Dimension) }\end{array}$} & \multirow{2}{*}{$\begin{array}{l}\text { Anchor } \\
\text { Sequence }\end{array}$} & \multicolumn{2}{|c|}{$\begin{array}{l}\text { Children } \\
\text { Phase }\end{array}$} & \multicolumn{2}{|c|}{$\begin{array}{l}\text { Retardates } \\
\text { Phase }\end{array}$} \\
\hline & & I & II & I & II \\
\hline Dark (Brightness) & $\begin{array}{l}1 / 2 \\
2 / 1\end{array}$ & $\begin{array}{l}2.688 \\
0.813\end{array}$ & $\begin{array}{l}1.813 \\
2.375\end{array}$ & $\begin{array}{l}2.500 \\
1.625\end{array}$ & $\begin{array}{l}1.000 \\
1.938\end{array}$ \\
\hline Rough (Texture) & $\begin{array}{l}1 / 2 \\
2 / 1\end{array}$ & $\begin{array}{l}2.438 \\
1.125\end{array}$ & $\begin{array}{l}1.625 \\
2.375\end{array}$ & $\begin{array}{l}2.188 \\
0.625\end{array}$ & $\begin{array}{l}1.563 \\
1.500\end{array}$ \\
\hline $\begin{array}{l}\text { Sad (Facial } \\
\text { Happiness) }\end{array}$ & $\begin{array}{l}1 / 2 \\
2 / 1\end{array}$ & $\begin{array}{l}2.438 \\
0.875\end{array}$ & $\begin{array}{l}1.125 \\
2.375\end{array}$ & $\begin{array}{l}2.063 \\
1.375\end{array}$ & $\begin{array}{l}1.250 \\
1.875\end{array}$ \\
\hline Tall (Height) & $\begin{array}{l}1 / 2 \\
2 / 1\end{array}$ & $\begin{array}{l}2.750 \\
0.313\end{array}$ & $\begin{array}{l}0.313 \\
2.375\end{array}$ & $\begin{array}{l}2.313 \\
0.500\end{array}$ & $\begin{array}{l}0.500 \\
2.063\end{array}$ \\
\hline Light (Weight) & $\begin{array}{l}1 / 2 \\
2 / 1\end{array}$ & $\begin{array}{l}1.813 \\
0.438\end{array}$ & $\begin{array}{l}0.500 \\
2.125\end{array}$ & $\begin{array}{l}2.063 \\
0.875\end{array}$ & $\begin{array}{l}0.688 \\
2.188\end{array}$ \\
\hline
\end{tabular}

Table 2

Summary of Phases by Anchor Sequence Interaction Effects Confirming Relational Judgments for Child and Retardate Samples

\begin{tabular}{lcc}
\hline \multicolumn{1}{c}{ Dimension } & \multicolumn{1}{c}{ Children } & Retardates \\
\hline Brightness & $\mathrm{F}(1,16)=28.70^{\dagger}$ & $\mathrm{F}(1,16)=17.52 \dagger$ \\
Texture & $\mathrm{F}(1,24)=20.04 \dagger$ & $\mathrm{F}(1,24)=12.52^{*}$ \\
Facial Happiness & $\mathrm{F}(1,16)=75.00^{\dagger}$ & $\mathrm{F}(1,16)=16.04 *$ \\
Height & $\mathrm{F}(1,16)=136.42 \dagger$ & $\mathrm{F}(1,16)=57.46 \dagger$ \\
Weight & $\mathrm{F}(1,24)=53.20^{\dagger}$ & $\mathrm{F}(1,24)=59.65 \dagger$ \\
\hline$\dagger<.001 * .005$ &
\end{tabular}

(dark, rough, sad, tall, and light) by experimental dimension and anchor sequence for both children and retardates in Phases I and II. It will be noted that consistent "crossovers" are shown in response to the shift in anchors between the phases.

Concordant with the pattern of means in Table 1, for both the children and retardates, analyses of variance revealed significant Phase by Anchor Sequence interaction terms in all experiments, supporting the prediction of relational judgments. These interaction effects are summarized in Table 2.

Scheffé tests confirmed that on all dimensions the children in each anchor sequence group considered separately shifted in the relational direction between phases (largest $p<.025$ ). A similar pattern was found among retardates, except for the anchor sequence $2 / 1$ group on brightness; all other shifts were significant (largest $\mathrm{p}<.05$ ).

Further, providing or omitting the visual prop never created significant main effects or interactions on any dimension for the children; their relational judgments must be attributed to cognitive mediation through memory, since viewing the anchor while judging visual test stimuli did not affect response. With retardates, an interaction of Visual Prop by Ability by Phases was found only on the brightness dimension $[F(1,16)=7.52$, $\mathrm{p}<.025]$, suggesting the smarter group made some use of the visual prop.

Age of child only affected the height dimension, where age interacted with anchor sequence $[F(1,16)=6.40, p<.025]$ and with Phases by Anchor Sequence $[F(1,16)=5.16, p<.05]$, such that younger children showed slightly less relational shift than older ones; the younger group gave more tall judgments in anchor sequence $1 / 2$ than in $2 / 1$, but the reverse held for older children. Test-stimulus order affected children only on the brightness dimension, where an Order by Phases interaction was found $[F(1,16)=5.45, p<.05]$. In short, the children's ages and conceptually irrelevant procedural variations had little effect on their relational judgments.

The retardates' responses were less robust across minor alterations. For example, significant interactions between test-stimulus order and other variates were found with the facial happiness, height, and weight dimensions (see Kelley, 1973). Ability level interacted with phases for weight judgments $[F(1,24)=5.73$, $p<.025]$, with the duller group judging more stimuli as 
Table 3

Summary of $t$ Values Showing Relational Judgments Among Test Stimuli by Phase and Dimension for Child and Retardate Groups

\begin{tabular}{|c|c|c|c|}
\hline \multirow{2}{*}{$\begin{array}{l}\text { Dimension } \\
\text { and Group }\end{array}$} & \multicolumn{3}{|c|}{ Phase } \\
\hline & I & II & III \\
\hline \multicolumn{4}{|l|}{ Brightness } \\
\hline Children & 1.44 & 0.00 & 0.00 \\
\hline Retardates & -0.33 & $3.48 \dagger$ & $5.11 \dagger \dagger$ \\
\hline \multicolumn{4}{|l|}{ Texture } \\
\hline Children & $2.40^{* *}$ & 1.36 & $1.72 *$ \\
\hline Retardates & 0.37 & 1.65 & $2.78+\dagger$ \\
\hline \multicolumn{4}{|c|}{ Facial Happiness } \\
\hline Children & $5.93+\dagger$ & $6.39 \dagger \dagger$ & $6.00+\dagger$ \\
\hline Retardates & $5.64 t \dagger$ & $6.39 \dagger \dagger$ & $8.26 \dagger \dagger$ \\
\hline \multicolumn{4}{|l|}{ Height } \\
\hline Children & $1.97 *$ & $2.40^{* *}$ & $3.30 \dagger$ \\
\hline Retardates & 1.28 & $3.57 \dagger$ & $6.31 \dagger \dagger$ \\
\hline \multicolumn{4}{|l|}{ Weight } \\
\hline Children & $3.75+\dagger$ & $4.38+\dagger$ & $3.78+\dagger$ \\
\hline Retardates & $4.10+t$ & $4.05 \dagger \dagger$ & $4.98+t$ \\
\hline${ }^{*} p<.10$ & $<.05$ & $t p<.01$ & $<.001$ \\
\hline
\end{tabular}

lighter. Ability also interacted with anchor sequence and phases on the brightness dimension $[\mathrm{F}(1,16)=6.02$, $\mathrm{p}<.05$ ], such that in anchor sequence $2 / 1$ the more severe retardates tended to shift away from the predicted judgmental contrast, but the brighter group made borderline relational shifts $(\mathrm{p}<.10)$.

\section{Within-Phases Judgments Among Test Stimuli}

Both for all children combined and for combined retardates, Table 3 presents by phase and dimension the $\mathrm{t}$ values (all $\mathrm{dfs}=31$ ) reflecting relational judgments.

One will note that 13 of the 15 ts for children were in the expected direction (11 attaining or approaching significance) and with two ties $(t=0)$. For the retardates, 14 of 15 ts were in the expected direction (11 attaining significance), with one reversal (ns) denoted by a "-" in the table. The directional consistency of these data appears to lend further support to the significant $t$ values, indicating that the judgments took some relational account of intensity differences among the test stimuli. There was a more pronounced relational pattern in Phase III when no anchors were given. Also, retardates showed rather stronger effects than children (the reverse of the main results), perhaps suggesting that the retardates were more responsive to the immediate test stimuli and were less affected by the anchors, more remote in time.

\section{DISCUSSION}

The present results seem an unambiguous demonstration of relational judgment processes in very young children. Judgmental shifts to accord with both alternative directions of extreme anchors were found for the five separate dimensions studied. Further, more subtle relational judgments based on smaller differences among the test stimuli were also obtained. The age variable only affected the height dimension; on all other dimensions the amounts of relational displacement were comparable for the younger and older groups, and the oldest child was only 5.3 years old. Also, exposing a visual anchor prop had no discernible effect on response. This suggests that the relational judgments were mediated through some central storage process and not through simultaneous comparisons between stimuli of differing values. It appears plausible that the more direct stimulus operations and simpler response formats presently used accounted for the relational judgments obtained, contrasting with the more complex indirect procedures of O'Reilly and Steger (1970), who failed to obtain any anchoring effects with children below age 6 .

In light of the strong relational judgments now reported, one may question Piaget's (1928) view that young children cannot think relationally, make judgments without regard to contextual frames of reference, and do not recognize that certain ideas (e.g., hard and soft) involve a relation between at least two members. Nor does his more recent writing suggest that Piaget (e.g., 1968) has substantially altered his earlier doubts about young children's capacity for even elementary relativism of thought.

It now would seem appropriate to conduct research to determine if, by suitable procedures, young children prove capable of more demanding relational feats, like seriation, or if they are capable of discriminating stimulus differences cast in psychophysical form to perhaps approximate psychophysical functions such as the classic Weber or Fechner equations.

\section{REFERENCES}

Bandura, A. Principles of behavior modification. New York: Holt, Rinehart, \& Winston, 1969.

Bandura, A. Social learning theory. New York: General Learning Press, 1971.

Helson, H. Adaptation level theory. New York: Harper \& Row, 1964.

Kelley, J. E. Some stimulus anchoring effects in young children. Unpublished MA thesis, University of Arizona, 1973.

McNemar, Q. Psychological statistics. (3rd ed.) New York: Wiley, 1962.

O'Reilly, E., \& Steger, J. A. Children's use of context in judgment of weight. Child Development, 1970, 41, 10951101.

Piaget, J. Judgment and reasoning in the child. New York: Harcourt-Brace, 1928.

Piaget, J. Six psychological studies. New York: Vintage, 1968.

Rosenthal, T. L., \& Kellogg, J. S. Demonstration versus instructions in concept attainment by mental retardates. Behaviour Research \& Therapy, 1973, 11, in press.

Rosenthal, T. L., \& White, G. M. Initial probability, rehearsal, and constraint in associative class selection. Journal of Experimental Child Psychology, 1972, 13, 261-274.

Rosenthal, T. L., \& Zimmerman, B. J. Modeling by exemplification and instruction in training conservation. Developmental Psychology, 1972, 6, 392-401.

Sherif, M., \& Hovland, C. I. Social judgment. New Haven, Conn: Yale University Press, 1961.

(Received for publication August 20, 1973; revision received September $17,1973$. 